\title{
Is the broad autism phenotype in mothers of children with autism spectrum disorder exacerbated by the challenges of caring for their children?
}

\author{
Jenny Fairthorne ${ }^{1 *}$, Colleen Fisher ${ }^{2}$ and Andrew J. O. Whitehouse ${ }^{1}$ \\ *Correspondence: Jenny.Fairthorne@telethonkids.org.au

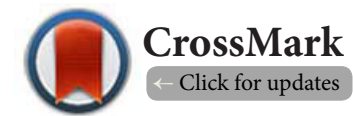

'Telethon Kids Institute, University of Western Australia, Perth, Western Australia.

${ }^{2}$ School of Population Health, University of Western Australia, Perth, Western Australia.

\begin{abstract}
Study purpose: This study raises the hypothesis that the additional demands of parenting a child with autism spectrum disorder (ASD) may lead to behavioural and personality changes consistent with the Broader Autism Phenotype (BAP).

Background: In a previous study, 16 mothers of children with ASD were interviewed about their quality of life. A number of mothers indicated that they believed the additional demands of parenting a child with ASD led to changes in their behaviour and personality. These changes are of particular interest in relation to the BAP, which refers to the presence of mild autistic traits in an individual. Researchers have typically used the existence of a BAP to indicate genetic liability for ASD. However, it is possible that behavioural and personality changes in response to parenting a child with ASD may be skewing scores on measures of the BAP, such as the Autism-Spectrum Quotient (AQ).

Presentation of hypothesis: This qualitative study of parental interviews provided a preliminary examination of whether behaviours consistent with the BAP may have been exacerbated by the challenges of raising a child with ASD.

Testing methods: Qualitative analyses from the previous study revealed that seven of the 16 mothers reported behavioural and personality changes since the onset of their child's ASD. We examine these behaviours in relation to the Autism-Spectrum Quotient and provided two potential designs for future studies to examine whether BAP-like behaviours may be exacerbated by parenting demands.

Implications of the hypothesis: A degree of caution is needed when researchers interpret measures of the BAP in parents who are full-time carers of their child with ASD. Some scores indicative of this phenotype may not solely represent a genetic liability for ASD. Longitudinal studies that explore the BAP among parents of children with ASD before, during and after the onset of caring will shed light on this complex research area.
\end{abstract}

Keywords: Autism, phenotype, mothers, autism spectrum disorders, genetic

\section{Introduction}

Seventy years ago, the child psychiatrist, Leo Kanner, described mothers of children with autism spectrum disorder (ASD) as distant and aloof [1]. This concept of milder autistic traits in the relatives of children with ASD has developed considerably. Typically, researchers take these milder autistic traits to be the phenotypic expression of a genetic predisposition to ASD and have named them the Broader Autism Phenotype (BAP) [2].
Expressions of the BAP in relatives of people with ASD have been utilised as a complementary tool to explore the genetics of ASD [3]. The Autism-Spectrum Quotient (AQ) is one method of assessing the BAP. Respondents indicate on a scale how well each of 50 behavioural statements applies to them (strongly agree, agree, disagree, strongly disagree) [4]. Responses indicative of autistic-like traits are scored ' 1 ' (strongly agree/agree or strongly disagree/disagree) and others, '0'. Consistently, parents 
Fairthorne et al. Journal of Autism 2014,

of children with ASD score more highly than other parents [5].

However, the position that the BAP reflects a genetic liability for ASD ignores other influences on parental behaviour. Many challenges arise from rearing a child with ASD such as reduced sleep [6], more expenses [7], stigma [8] and managing violent or self-harming behaviours [9]. Currently, researchers have not considered that these challenges may influence parental BAP-like behaviours.

\section{Presentation of hypothesis}

The first author interviewed 16 mothers of children with ASD [10]. There was no aim to examine the BAP but data relevant to this area emerged through our phenomenological analysis [11]. Seven of the mothers reported behavioural or personality changes since the onset of their child's ASD.

For example, when asked if her daughter's disability impacted on social relationships, one mother explained: 'My personality has changed too. I used to love fun and loved to get with people and have a great time'. Furthermore, she no longer enjoyed planning for the future and no longer bothered.

Another, when questioned about employment, detailed her enormous efforts of child-rearing and added that autism had put 'bad grooves in her personality'.

Attitudes towards social relationships were fundamentally altered following their child's diagnosis. Mothers were asked if they had ever felt included/excluded because of their child's disability?

In response, some spoke of the difficulty of retaining old friends and instigating new friendships. One mother expounded: 'You can't really go out with your friends anymore... You'd have to run after your child. You can't just sit down and say have a coffee...'

Another explained: 'You don't visit people. You don't have friends'. Two others spoke of their lack of time and energy to socialise. The first reported: 'I didn't have a social life... It takes effort to make friends. You have to reciprocate... There was nothing that I could do apart from care for my children'.

The other reflected: I' I've also lost interest in going out. I'm tired and so I just don't have the energy to do the sort of partying that I was involved with before... I became incredibly socially isolated because the moment I tried to have a conversation, my child would run away'.

In Table 1, several of these comments align with items mapping on to the 'Social Skill' subscale of the AQ.

Given the clear concordance between some mothers responses and items on the $A Q$, it is possible that BAP-like behaviours may increase after the onset of caring for a child with ASD. We hypothesize that BAP-like behaviours are not solely a gen-etic liability for ASD, but also a response to the challenges of parenting a child with ASD.

\section{Testing the hypothesis}

Hypothesis testing is problematic since parents are not identifiable until after their child's diagnosis. A suitable longitudinal
Table 1. Alignment of personality changes in mothers after a child's diagnosis with autism with items on the autism spectrum quotient.

\begin{tabular}{ll}
\hline Autism spectrum quotient item & Mother's comment \\
\hline $\begin{array}{l}\text { 1. I prefer to do things on my } \\
\text { own rather than with others }\end{array}$ & $\begin{array}{l}\text { I haven't had the time, the } \\
\text { energy or the inclination to go } \\
\text { and make friends }\end{array}$ \\
$\begin{array}{l}\text { 11. I find social situations easy } \\
\text { (reverse scored) }\end{array}$ & $\begin{array}{l}\text { I became incredibly socially } \\
\text { isolated because the moment } \\
\text { I tried to have a conversation } \\
\text { my child would run away }\end{array}$ \\
\hline $\begin{array}{l}\text { 22. I find it hard to make new } \\
\text { friends }\end{array}$ & $\begin{array}{l}\text { You can't really go out with } \\
\text { your friends anymore... you'd } \\
\text { have to run after your child. } \\
\text { You can't just sit down and say } \\
\text { have a coffee. You're always } \\
\text { looking out the side there, } \\
\text { wondering where she is }\end{array}$ \\
& $\begin{array}{l}\text { I've also lost interest in going } \\
\text { out }\end{array}$ \\
\hline 44. I enjoy social situtations
\end{tabular}

study could be a large-scale 'birth cohort' study, which administers the $A Q$ to mothers at points throughout their child's life. We would predict a significant interaction between $A Q$ scores of mothers of children with ASD and mothers of typically developing children when examined during their child's early (i.e., pre-diagnosis) and later (i.e., post-diagnosis) life. Given the infrequency of ASD occurrence, such a design might be prohibitively expensive. However there are already several large birth-cohort studies in existence (Avon Longitudinal Study of Parents and Children (ALSPAC) [12] and Generation $R$ [13]) that could provide an opportunity for hypothesis testing. In a cross-sectional study, researchers could recruit two groups of parents: (a) full-time carers cohabiting with their child and (b) former carers, no longer cohabiting with their child. A between-groups comparison of AQ scores would provide useful data for hypothesis testing.

\section{Implications of the hypothesis}

Our analyses did not identify similarities between mother responses and items pertaining to other scales on the $A Q$, such as Attention to Detail, Attention Switching and Communication and Imagination. However, we note that 'false-positives' on even one scale, can substantially influence interpretation of data. For example, mothers endorsing all items presented in Table 1, would score ' 4 ' for the 'Social Skills' subscale, which is a score indicative of the BAP in this subscale [5]. However, rather than solely reflecting a genetic liability for ASD, the nature and context of these mothers comments indicate that this score may also emphasize the difficulties with social relationships that accompany having a child with ASD.

Compare Kanner's description of mothers of children with ASD in his clinic to the following insight provided by a similar mother, 70 years later. She had made the decision to be very unemotional when talking to professionals about her son and 
acknowledged the following coping mechanism.

'If I let myself get emotional with one of these people and with one of their questions, I thought the flood-gates are going to open and I'm never going to be able to get myself back from it'. In a similar way to Kanner, her husband reported 'You come across as very cold-hearted'.

These preliminary data urge caution when interpreting the scores of the $A Q$ and other BAP assessments, particularly in the domains of social engagement and enjoyment. Behaviours consistent with the BAP may not solely represent a genetic liability for ASD, and scores on these assessments may be inflated by responses to having a child with disability.

\section{List of abbreviations}

ASD: Autism Spectrum Disorder

BAP: Broader Autism Phenotype

AQ: Autism-Spectrum Quotient

ALSPAC: Avon Longitudinal Study of Parents and Children

Competing interests

The authors declare that they have no competing interests.

Authors' contributions

\begin{tabular}{|l|c|c|c|}
\hline Authors' contributions & JF & CF & AJOW \\
\hline Research concept and design & $\checkmark$ & $\checkmark$ & $\checkmark$ \\
\hline Collection and/or assembly of data & $\checkmark$ & $\checkmark$ & $\checkmark$ \\
\hline Data analysis and interpretation & $\checkmark$ & $\checkmark$ & $\checkmark$ \\
\hline Writing the article & $\checkmark$ & -- & $\checkmark$ \\
\hline Critical revision of the article & $\checkmark$ & -- & $\checkmark$ \\
\hline Final approval of article & $\checkmark$ & $\checkmark$ & $\checkmark$ \\
\hline Statistical analysis & $\checkmark$ & -- & $\checkmark$ \\
\hline
\end{tabular}

Acknowledgement and funding

We gratefully acknowledge the support of the Autism Association of Western Australia for their assistance with recruiting and the generosity and honesty of the 16 mothers who participated in the initial study. An Australian Post-graduate Award enabled the first author to conduct the precursor study and write this manuscript.

Publication history

Editors: Jean Ann Summers, University of Kansas, USA.

Peggy A. Gallagher, Georgia State University, USA.

Received: 21-Jun-2014 Final Revised: 04-Sep-2014

Accepted: 06-Sep-2014 Published: 19-Sep-2014

\section{References}

1. Kanner L. Autistic disturbances of affective contact. Nervous child. 1943; 2:217-50. | Pdf

2. Hurley RS, Losh M, Parlier M, Reznick JS and Piven J. The broad autism phenotype questionnaire. J Autism Dev Disord. 2007; 37:1679-90. | Article | PubMed

3. Piven J. The broad autism phenotype: a complementary strategy for molecular genetic studies of autism. Am J Med Genet. 2001; 105:34-5. | PubMed

4. Baron-Cohen S, Wheelwright S, Skinner R, Martin J and Clubley $\mathrm{E}$. The autism-spectrum quotient (AQ): evidence from Asperger syndrome/high-functioning autism, males and females, scientists and mathematicians. J Autism Dev Disord. 2001; 31:5-17. | Article | PubMed
5. Bishop DV, Maybery M, Maley A, Wong D, Hill W and Hallmayer J. Using self-report to identify the broad phenotype in parents of children with autistic spectrum disorders: a study using the Autism-Spectrum Quotient. J Child Psychol Psychiatry. 2004; 45:1431-6. | Article | PubMed

6. Polimeni MA, Richdale AL and Francis AJ. A survey of sleep problems in autism, Asperger's disorder and typically developing children. J Intellect Disabil Res. 2005; 49:260-8. | Article | PubMed

7. Twoy R, Connolly PM and Novak JM. Coping strategies used by parents of children with autism. J Am Acad Nurse Pract. 2007; 19:251-60. I Article I PubMed

8. Mak WW and Kwok YT. Internalization of stigma for parents of children with autism spectrum disorder in Hong Kong. Soc Sci Med. 2010; 70:2045-51. | Article | PubMed

9. Billstedt E, Gillberg IC and Gillberg C. Autism after adolescence: population-based 13- to 22-year follow-up study of $\mathbf{1 2 0}$ individuals with autism diagnosed in childhood. J Autism Dev Disord. 2005; 35:351-60. | Article I PubMed

10. Fairthorne J, Fisher C, Bourke J and Leonard H. Experiences impacting the quality of life of mothers of children with autism and intellectual disability. Psychology Research. "In press". 2014; 4:666-684.

11. Van Manen M. Researching lived experience: human science for an action sensitive pedagogy. New York: State University of New York Press; 1990.

12. Golding J, Pembrey M and Jones R. ALSPAC--the Avon Longitudinal Study of Parents and Children. I. Study methodology. Paediatr Perinat Epidemiol. 2001; 15:74-87. | Article | PubMed

13. Jaddoe VW, Bakker R, van Duijn CM, van der Heijden AJ, Lindemans J, Mackenbach JP, Moll HA, Steegers EA, Tiemeier H, Uitterlinden AG, Verhulst FC and Hofman A. The Generation R Study Biobank: a resource for epidemiological studies in children and their parents. Eur J Epidemiol. 2007; 22:917-23. | Article | PubMed Abstract | PubMed Full $\underline{\text { Text }}$

\section{Citation:}

Fairthorne J, Fisher C and Whitehouse AJO. Is the broad autism phenotype in mothers of children with autism spectrum disorder exacerbated by the challenges of caring for their children? J Autism. 2014; 1:2. http://dx.doi.org/10.7243/2054-992X-1-2 